\title{
Autosomal dominant spastic ataxia type 1
}

INSERM

\section{Source}

INSERM. (1999). Orphanet: an online rare disease and orphan drug data base. Autosomal dominant spastic ataxia type 1. ORPHA:251282

A rare, genetic, autosomal dominant spastic ataxia disorder characterized by lower-limb spasticity and ataxia in the form of head jerks, ocular movement abnormalities, dysarthria, dysphagia and gait disturbances. 